\title{
Comparison of TC Temperature and Water Vapor Climatologies between the Atlantic and Pacific Oceans from GPS RO Observations
}

\author{
S. YANG \\ Joint Center of Data Assimilation for Research and Application, Nanjing University of Information Science and \\ Technology, Nanjing, China \\ X. ZOU \\ Earth System Science Interdisciplinary Center, University of Maryland, College Park, College Park, Maryland \\ P. S. RAY \\ Department of Earth, Ocean, and Atmospheric Science, Florida State University, Tallahassee, Florida
}

(Manuscript received 13 February 2018, in final form 2 August 2018)

\begin{abstract}
Tropical cyclone (TC) temperature and water vapor structures are essential atmospheric variables. In this study, global positioning system (GPS) radio occultation (RO) observations from the GPS RO mission named the Constellation Observing System for Meteorology, Ionosphere, and Climate and the Global Navigation Satellite System (GNSS) Receiver for Atmospheric Sounding on board both $\mathrm{MetOp}-\mathrm{A}$ and $\mathrm{MetOp}-\mathrm{B}$ satellites over the 9-yr period from 2007 to 2015 are used to generate a set of composite structures of temperature and water vapor fields within tropical depressions (TDs), tropical storms (TSs), and hurricanes (HUs) over the Atlantic Ocean and TDs, TSs, and typhoons (TYs) over the western Pacific Ocean. The composite TC structures are different over the two oceanic regions, reflecting different climatological environments. The warm cores for TCs over the western Pacific Ocean have higher altitudes and larger sizes than do those over the Atlantic Ocean for all storm categories. A radial variation of the warm-core temperature anomaly with descending altitude is seen, probably resulting from spiral cloud and rainband features. The large TC water vapor pressure anomalies, which are often more difficult to obtain than temperature anomalies, are located below the maximum warm-core temperature anomaly centers. Thus, the maximum values of the fractional water vapor pressure anomaly, defined as the anomaly divided by the environmental value, for TSs and HUs over the Atlantic Ocean (1.4\% for TSs and 2.2\% for HUs) are higher than those for TSs and TYs over the western Pacific Ocean (1.2\% for TSs and $1.4 \%$ for TYs). These TC structures are obtained only after a quality control procedure is implemented, which consists of a range check that removes negative refractivity values and unrealistic temperature values, as well as a biweight check that removes data that deviate from the biweight mean by more than 3 times the biweight standard deviation. A limitation of the present study is an inability to resolve the TC inner-core structures because of a lack of sufficient RO profiles that collocate with TCs in their inner-core regions and the relatively coarse along-track resolutions of GPS RO data.
\end{abstract}

\section{Introduction}

Global warming leads to warmer ocean temperatures and higher sea levels, which could lead to more occurrences of the most intense hurricanes (HUs; Knutson et al. 2010). Although satellite remote sensing and computer technologies have experienced rapid advances, differences in tropical cyclone (TC) temperature

Corresponding author: Dr. Xiaolei Zou, xzou1@umd.edu and water vapor climatologies between the Atlantic and Pacific Oceans are not well known, which is partly associated with insufficiently accurate large-scale global analyses/reanalyses and predictions of the track, intensity, and structural changes of TCs (Cangialosi and Franklin 2011; Gall et al. 2013). Out of the many factors that could contribute to these difficulties, vortex initialization is an important factor that limits the accuracy of the analysis/reanalysis and forecast skill of TCs. This study is relevant to the use of satellite observations for 
obtaining the TC structural climatologies of temperature and water vapor fields, which could be used for vortex initialization over the Atlantic and Pacific Oceans.

In general, if a vortex in a 6-h forecast field is too weak and does not have a clearly defined TC structure, a bogus vortex needs to be added to the initial model state. A bogus vortex was often generated from empirical specifications of the TC wind field (Kurihara et al. 1990, 1993; Lord 1991; Trinh and Krishnamurti 1992) or TC mass field (Fujita 1952; Zou and Xiao 2000; Xiao et al. 2000), model forecasts ( $\sim 48 \mathrm{~h}$; Liu et al. 1997), and fourdimensional variational (4D-Var) analyses (Zou and Xiao 2000; Park and Zou 2004). Many TC structural features are contained in bogus vortices, including anomalous warm cores in the mid- and upper troposphere; the lowest sea surface pressure and the maximum surface wind that match the observed values at initial times of model forecasts; an eyewall, saturated ascent around the eye, and descent or weak ascent in the eye; or even the spiral cloud and rainband features of TCs. The vortices currently used in the Hurricane Weather Research and Forecasting (HWRF) Model (Janjic et al. 2001; Janjic 2003) consist of two bogus vortices stored in data format (see figures below): one for deep TCs and the other for shallow- and mediumdepth TCs (Zou et al. 2013, 2015). These bogus vortices of winds and temperatures are scaled empirically for forecasting a real TC whose radii of the maximum wind, outermost closed isobar, and maximum wind speed are known. The mixing ratio is modified based on the scaled temperature under the constraint that relative humidity does not change. It is therefore necessary to explore the potential of GPS ROs for obtaining TC structures.

Nowadays, advances in satellite remote sensing technologies provide abundant global observations of various structural features of different state variables within and around TCs. An advantage of using satellite observations is that they provide measurements not only over the Atlantic, but also over the Pacific Ocean. Assimilation of high-resolution direct inner-core observations from aircraft, dropsonde, and polar-orbiting and geostationary satellite radiance observations allowed hurricane data assimilation and forecasts to gradually move away from using bogus vortex or retrieved products (Zhang et al. 2009, 2016; Honda et al. 2018). TC inner-core structures over the Atlantic Ocean were studied using airborne Doppler radar observations (Marks and Houze 1987). Such observations are not available for the Pacific Ocean. Having a set of properly constructed initial vortices to include into the background field is likely sufficient in TC satellite data assimilation for generating a long-term reanalysis and/or analysis for HU forecasts. Specifically, historic global positioning system (GPS) radio occultation (RO) data will be used to first create a vortex background. GPS RO and other meteorological observations around the initial times of HU forecasts will then be assimilated to generate model initial conditions. HU forecasts will finally be made using the model initial conditions generated by bogusing and data assimilation. This study aims at generating a set of composite TC structures of temperature and water vapor fields within tropical depressions (TDs), tropical storms (TSs), typhoons (TYs), and HUs over the Pacific and Atlantic Oceans using observations from the GPS RO mission named Constellation Observing System for Meteorology, Ionosphere, and Climate (COSMIC) and the Global Navigation Satellite System (GNSS) Receiver for Atmospheric Sounding (GRAS) on board both $M e t O p$ - $A$ and $M e t O p-B$ satellites over the 9-yr period from 2007 to 2015 and within $1000 \mathrm{~km}$ from the respective TC center positions. It is noted that the exact TC inner-core structure within the $100-\mathrm{km}$ radial distances could be difficult to obtain from GPS RO data due to their coarse horizontal resolutions.

The paper is arranged as follows. Section 2 describes GPS RO data employed in this study and the quality control (QC) procedure used to remove outliers. Collocations between ROs and TCs over the Pacific and Atlantic Oceans and spatial distributions of ROs collocated with TCs are provided in section 3. Section 4 compares the GPS RO-derived TC structural differences in temperature, water vapor pressure, and refractivity of the TDs, TSs, and TYs/HUs between the western Pacific and the Atlantic Oceans. The importance of the QC is discussed in section 5. A summary and conclusions are provided in section 6 .

\section{GPS RO data description and QC}

GPS RO vertical profiles employed in this study come from the COSMIC, MetOp-A, and $\mathrm{Met} O p-B$ satellites, each with one receiver. The COSMIC satellite system was launched on 15 April 2006. It consists of a constellation of six low Earth orbit microsatellites (Anthes et al. 2008). The MetOp-A and MetOp-B satellites, carrying the GRAS with one GPS receiver, were launched on 19 October 2006 and 17 September 2012, respectively. MetOp-A and MetOp-B are the first two in a series of three polar-orbiting meteorological satellites that form the space segment component of the European Organization for the Exploitation of Meteorological Satellites Polar System.

The RO level-2 data used in this study are from the COSMIC and GRAS receivers during a 9-yr period from 2007 to 2015 and are provided by the University 
Corporation for Atmospheric Research COSMIC Data Analysis and Archival Center (CDAAC; Kuo et al. 2004). Vertical profiles of temperature, water vapor, and pressure were derived using a one-dimensional variational (1D-Var) wet retrieval algorithm (http://cosmicio.cosmic.ucar.edu/cdaac/doc/documents/1dvar.pdf). The European Centre for Medium-Range Weather Forecasts (ECMWF) analyses were used as the first guess field. The RO profiles are functions of geometric height above the sea level. COSMIC RO data from CDAAC version 3 are available from 1 January 2007 to 30 April 2014. MetOp-A GRAS RO data are available from 1 October 2007 to 31 December 2015, and $M e t O p-B$ GRAS RO data are available from 1 February 2013 to 31 December 2015. Since the vertical structures of atmospheric temperature and water vapor throughout the troposphere and lower stratosphere are the main focus of this paper, only RO profiles that penetrate below the mean sea level threshold of $800 \mathrm{hPa}$ are used. A two-step $\mathrm{QC}$ procedure is carried out for $\mathrm{RO}$ data selection. The first QC step is a range check, which eliminates those RO profiles that did not penetrate to a sufficiently low level defined by the threshold value of $800 \mathrm{hPa}$. This step also removes those data with negative refractivity or with temperature values lower than $-150^{\circ} \mathrm{C}$ and higher than $80^{\circ} \mathrm{C}$ in the height range below $50 \mathrm{hPa}$.

The second QC step eliminates observation outliers. A common procedure is to first estimate the mean and standard deviation of a variable of interest and then to reject those observations with values greatly deviating from the mean (i.e., more than several times the standard deviation). However, estimators of the traditional mean and standard deviation are sometimes greatly distorted in the presence of a small percentage of outliers, making the identification of outliers difficult. To avoid this situation, the biweight method proposed by Lanzante (1996) and applied to GPS RO data by Zou and Zeng (2006) is used to estimate the mean and standard deviation. A brief description of how the RO outliers are identified follows. Given a sample series $\left\{X_{i}\right.$, $i=1,2, \ldots, n\}$, the biweight mean (BM) and biweight standard deviation (BSD) are first defined as

$$
\begin{gathered}
\operatorname{BM}\left(X_{i}\right)=M+\frac{\sum_{i=1}^{n}\left(1-w_{i}^{2}\right)^{2}\left(X_{i}-M\right)}{\sum_{i=1}^{n}\left(1-w_{i}^{2}\right)^{2}}, \\
\operatorname{BSD}\left(X_{i}\right)=\frac{\left[n \sum_{i=1}^{n}\left(1-w_{i}^{2}\right)^{4}\left(X_{i}-M\right)^{2}\right]^{1 / 2}}{\left|\sum_{i=1}^{n}\left(1-w_{i}^{2}\right)\left(1-5 w_{i}^{2}\right)\right|},
\end{gathered}
$$

where $M$ is the median, MAD is the median of the absolute deviations from the median of the data, and $w_{i}$ $(i=1,2, \ldots, n)$ are weighting coefficients that are defined as

$$
w_{i}=\frac{X_{i}-M}{7.5 \times \mathrm{MAD}} .
$$

The estimated values of the BM and BSD from all RO data are less affected by the presence of outliers than the traditional estimators of the mean and standard deviation.

Finally, for each data point, a so-called $Z$ score can be calculated based on the following formula:

$$
Z_{i}=\frac{X_{i}-\mathrm{BM}\left(X_{i}\right)}{\mathrm{BSD}} .
$$

In this study, $\mathrm{RO}$ data with a $Z$ score greater than 3 are taken as outliers and removed in the second QC step. More details are given by Zou and Zeng (2006). Figure 1 presents scatterplots of the vertical variations in ROobserved refractivity observations collocated with TCs during the 9-yr period from 2007 to 2015 . Outliers removed by the first range check QC step concerning refractivity and temperature, as well as the second $Z$-score QC step, are shown in blue, green, and red, respectively. It is clear that the first range check QC step for both refractivity and temperature is necessary for removing those "out of the family" outliers. The second biweight QC step identifies most of the remaining outliers. All RO data collocated with TDs over the Atlantic Ocean after the range check on refractivity pass the range check on temperature. Very few RO data points collocated with TYs above $200 \mathrm{hPa}$ over the western Pacific Ocean after the range check on refractivity did not pass the range check on temperature. The impacts of outliers on generating composite TC temperature and water vapor climatologies for the Atlantic and Pacific Oceans from GPS RO observations are discussed in section 5. Figure 2 shows the spatial distributions of outliers removed by the two QC steps over the western Pacific and Atlantic Oceans. The outliers are randomly distributed with no obvious preferred location.

The RO profile counts removed by the first and second QC steps are provided in Fig. 3a. The largest number of outliers (4\%) is identified for HUs over the Atlantic Ocean. The percentage of RO data removed by the range check is less than $0.5 \%$ above $850 \mathrm{hPa}$. The altitude range below $600 \mathrm{hPa}$ has the largest number of outliers $(3 \%-5 \%)$ identified by the second QC step for TC-collocated ROs over the western Pacific Ocean, but not over the Atlantic Ocean. Another altitude range with the second-largest number of outliers identified by 

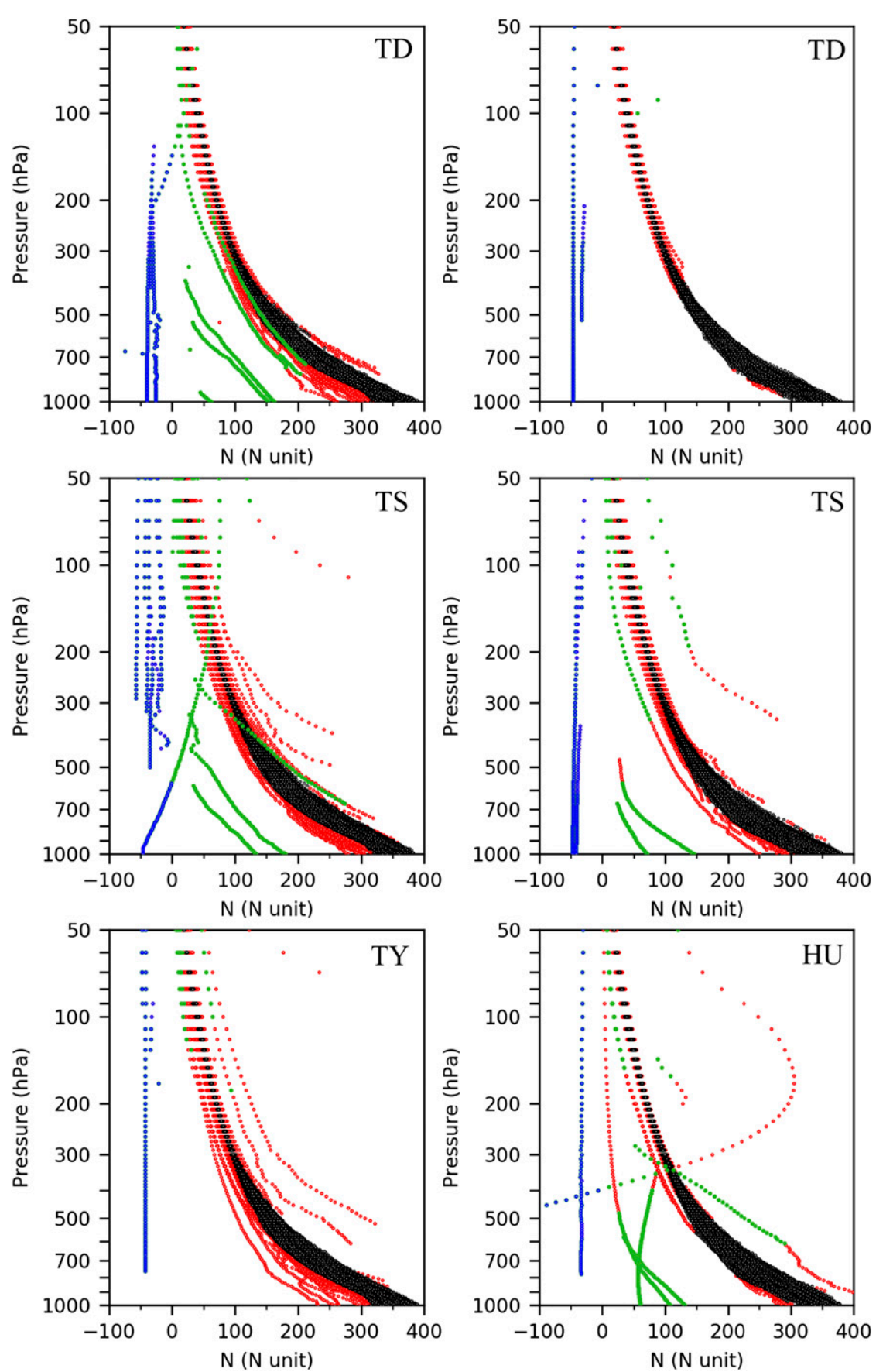

FIG. 1. Scatterplots of RO refractivity observations collocated with TCs in the TD, TS, and TY/HU categories over the (left) western Pacific and (right) Atlantic Oceans, removed by the first QC step (the range check on refractivity and temperature, in blue and green, respectively) and by the second $Z$-score QC step (in red). The black points represent data that pass QC.

the second QC step is located above $250 \mathrm{hPa}$ for TCcollocated ROs over both the Pacific $(2 \%-4.5 \%)$ and Atlantic $(1 \%-2.5 \%)$ Oceans. This second height region above $250 \mathrm{hPa}$ with a large number of outliers is consistent with results presented by Zou and Zeng (2006, see their Fig. 4a). Further investigations are needed to see if the Abel integral inversion, which derives the refractivity from the bending angle under the assumption of local spherical symmetry, sometimes introduces significant errors in RO refractivity in the tropopause. 

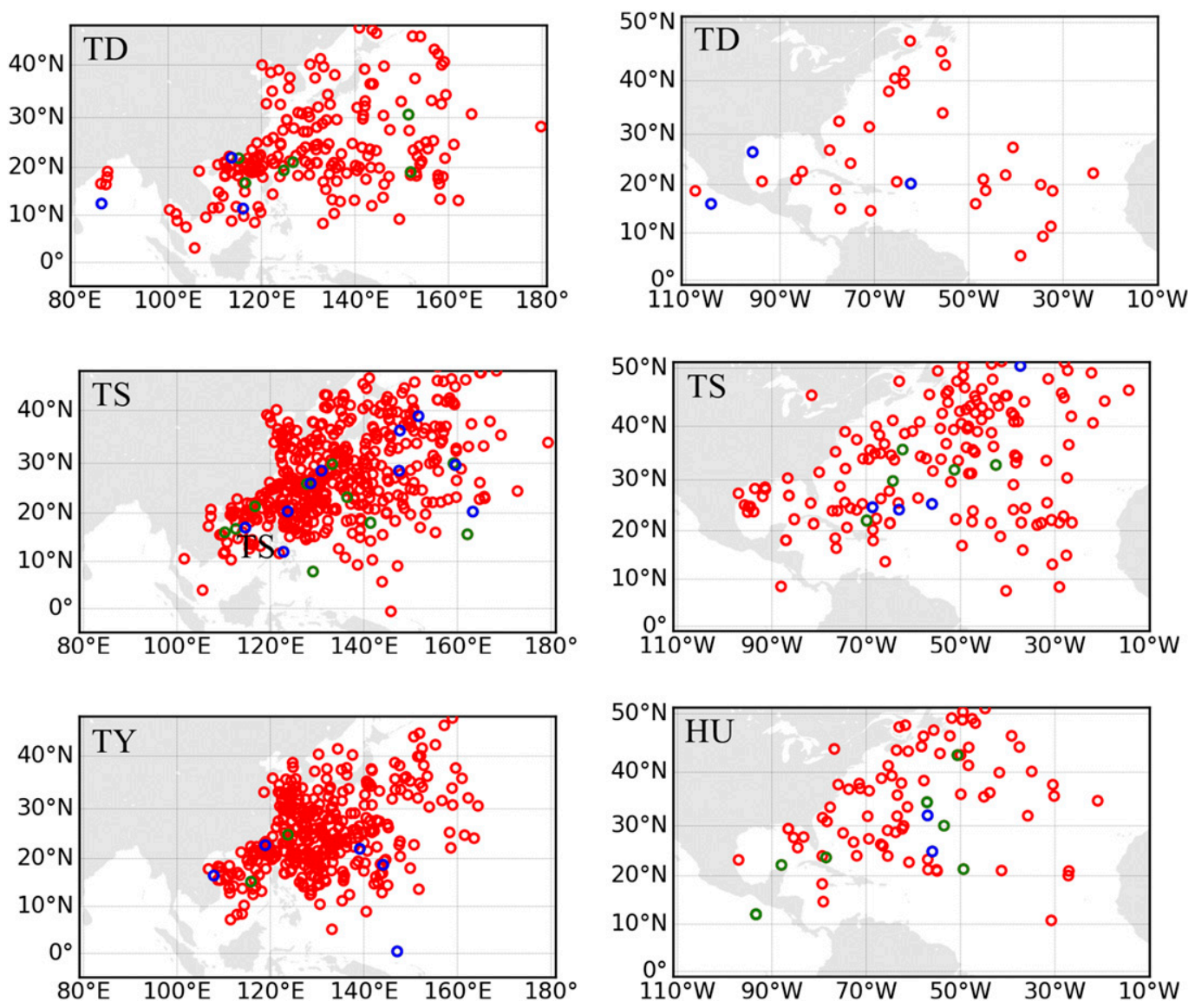

FIG. 2. Spatial distributions of outliers removed by the first QC step (the range check on refractivity and temperature, in blue and green, respectively) and by the second $Z$-score QC step (in red) over the (left) western Pacific and (right) Atlantic Oceans.

Figure $3 \mathrm{~b}$ shows the BSDs and the reductions in the BSDs of RO refractivity observations after QC checks were done for data collocated with TDs, TSs, and TYs over the western Pacific Ocean and with TDs, TSs, and HUs over the Atlantic Ocean. Although less than $5 \%$ of the RO data are removed by the two-step QC procedure, the standard deviations are significantly reduced, especially in the lower troposphere $(\sim 0.7 \mathrm{~N}$ units). A small reduction in the BSD is also found around $110 \mathrm{hPa}$.

\section{Collocation between ROs and TCs and their spatial distributions}

The collocation criteria between TC cases and RO profiles are set to a temporal difference of less than $3 \mathrm{~h}$ and a radial distance of less than $1000 \mathrm{~km}$ from TC centers. Figure 4 shows annual variations in the number of TC cases in the TD, TS, and TY/HU categories over the western Pacific (Fig. 4a) and Atlantic (Fig. 4b) Oceans, as well as the number of $\mathrm{RO}$ profiles from
COSMIC, MetOp- $A$, and MetOp-B during the 9-yr period from 2007 to 2015. The number of TCs over the western Pacific Ocean is significantly larger $(\sim 4$ times larger) than that over the Atlantic Ocean. The number of TC cases is the smallest in 2010 and the largest in 2015 over the western Pacific Ocean (Fig. 4a). Over the Atlantic Ocean, more TCs are found in the years 2008 and 2010-12 than in other years (Fig. 4b). The numbers of collocated ROs within and around TDs, TSs, and TYs over the western Pacific Ocean are more than twice those of ROs within and around TDs, TSs, and HUs over the Atlantic Ocean. The availability of ROs from GRAS on board MetOp-A and MetOp-B alleviates the significant reduction in COSMIC data because of the lack of reprocessed version $3 \mathrm{RO}$ data during the typhoon and hurricane seasons of 2014 and 2015.

The geographical distributions of the TC centers over the western Pacific and Atlantic Oceans are shown in Figs. 5 and 6, respectively. TDs over the western Pacific Ocean are located within $105^{\circ}-165^{\circ} \mathrm{E}$ and $5^{\circ}-30^{\circ} \mathrm{N}$ (Fig. 5a). As TCs' intensities increase to TSs and TYs, 
(a)

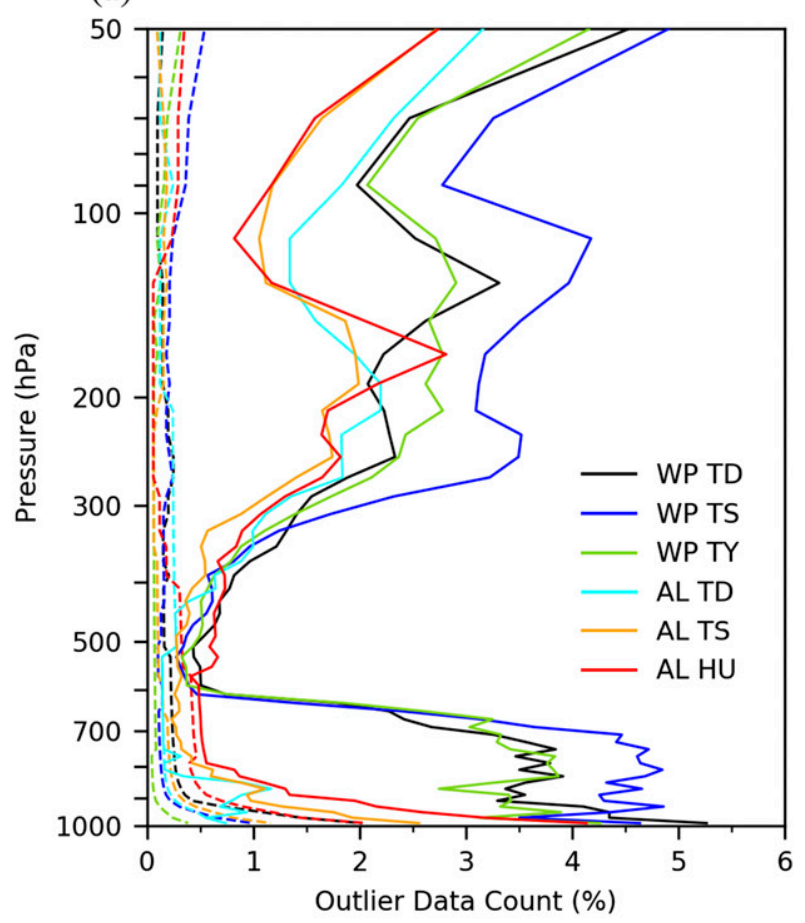

(b)

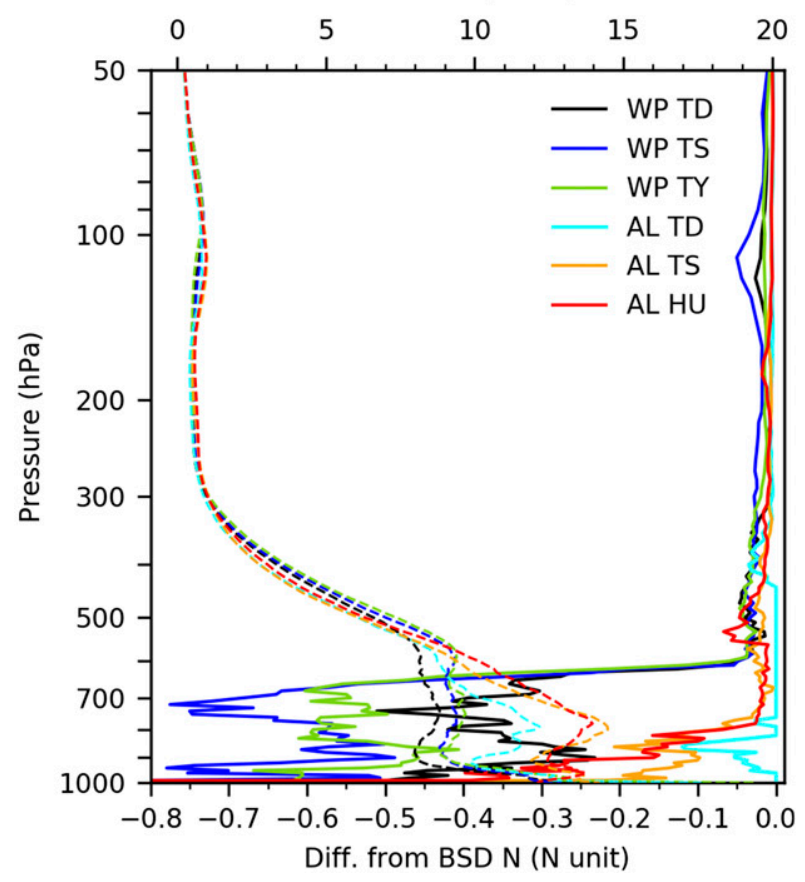

FIG. 3. (a) Percentage of RO refractivity observations removed by the first (dashed lines) and second (solid lines) QC steps and (b) BSDs of refractivity (dashed lines; top abscissa) and reductions in BSDs (solid lines; bottom abscissa) due to the QC over the western Pacific and Atlantic Oceans. (a)
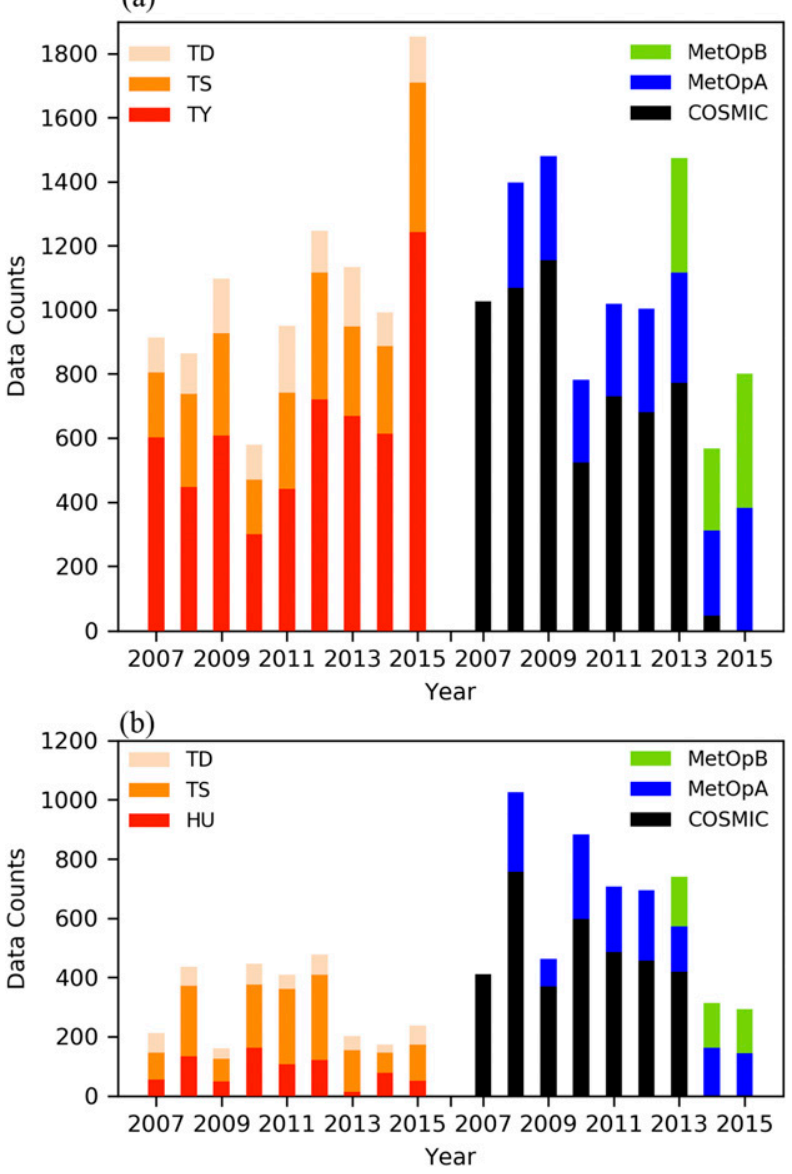

FIG. 4. Annual variations in the number of TC cases in the TD (pink), TS (orange), and TY/HU (red) categories over (a) the western Pacific Ocean and (b) the Atlantic Ocean, as well as the number of RO profiles from COSMIC (black), MetOp-A (blue), and $M e t O p-B$ (green) from 2007 to 2015 . The collocation criteria are set as follows. Temporal differences are less than $3 \mathrm{~h}$, and radial distances from the centers of TCs are less than $1000 \mathrm{~km}$.

their geographical distributions shift northwestward, as expected, considering the earth's rotation-induced beta effect in the Northern Hemisphere (Elsberry 1995). The region that is populated with TYs is confined to $105^{\circ}-$ $155^{\circ} \mathrm{E}$ and $10^{\circ}-35^{\circ} \mathrm{N}$ (Fig. $5 \mathrm{c}$ ). TYs are more concentrated and closer to land than both TDs and TSs over the western Pacific Ocean. There are more TYs than TDs and TSs over the western Pacific (Figs. 5 and 4a). TDs over the Atlantic Ocean are much less densely distributed and are spread out in wider longitudinal $\left(20^{\circ}-100^{\circ} \mathrm{W}\right)$ and latitudinal bands $\left(10^{\circ}-35^{\circ} \mathrm{N}\right.$; Fig. 6a), compared with TDs over the western Pacific Ocean (Fig. 5a). The number of TSs is larger than both TDs and HUs over the Atlantic Ocean (Figs. 6 and 4b). RO data from three satellite missions (i.e., COSMIC, MetOp-A, and $M e t O p-B$ ) are found within and around all categories of storm over both 

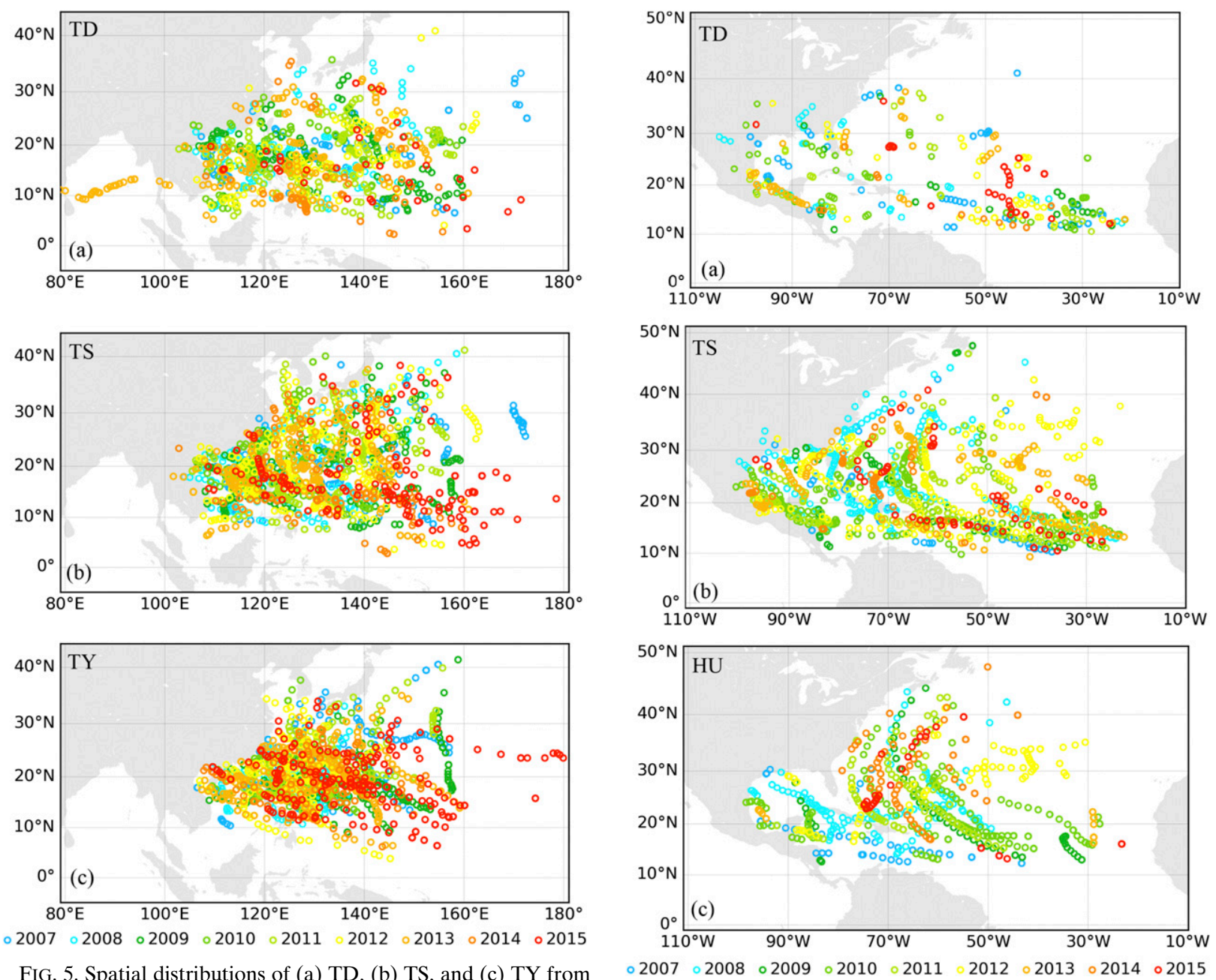

FIG. 5. Spatial distributions of (a) TD, (b) TS, and (c) TY from 2007 to 2015 for the western Pacific Ocean. Different years are indicated by different colors.

oceans (figures omitted). The geographical locations of HUs have a clear annual variability (Fig. 6c). The 2015 HUs are located more to the east and at higher latitudes than HUs in 2007 and 2008. TSs and HUs over the Atlantic Ocean are found only at low latitudes between $10^{\circ}$ and $20^{\circ} \mathrm{N}$.

\section{Comparison of TC structures between Atlantic and western Pacific Oceans}

GPS ROs have a high vertical resolution of $\sim 200 \mathrm{~m}$ and relatively coarser horizontal resolutions of $\sim 1.5$ (cross track) and $\sim 300 \mathrm{~km}$ (along track; Kursinski et al. 1996). They are ideal for constructing cross-sections of TC structures due also to weak sensitivity to cloud. To ensure that we have sufficient data samples to do so, RO data counts in each $50-\mathrm{km}$ radial distance and $10-\mathrm{hPa}$ pressure box are separately calculated for TDs, TSs, and

TYs over the western Pacific Ocean and for TDs, TSs, and HUs over the Atlantic Ocean (Fig. 7). It is noted that the data counts within the $200-\mathrm{km}$ radial distances of TC cores are quite limited (fewer than $\sim 40$ ), especially over the Atlantic Ocean. Variations in RO data counts with altitude are nearly constant above 500$600 \mathrm{hPa}$ and decrease with decreasing distance above sea level in the lower troposphere. The tropopauses for TYs (HUs) are higher than those for TDs and TSs over the Pacific (Atlantic) Ocean. The tropopause altitudes of TDs, TSs, and TYs over the western Pacific are higher than those of TDs, TSs, and HUs over the Atlantic Ocean. RO data are found in all radial distance bins, except near TD centers (i.e., less than $50 \mathrm{~km}$ from the centers).

Composite cross-sections of temperature and water vapor pressure within $1000-\mathrm{km}$ radial distances are shown in Figs. 8 and 9, respectively. Also shown in Figs. 8 and 9 are the tropopause heights derived from all 
TD
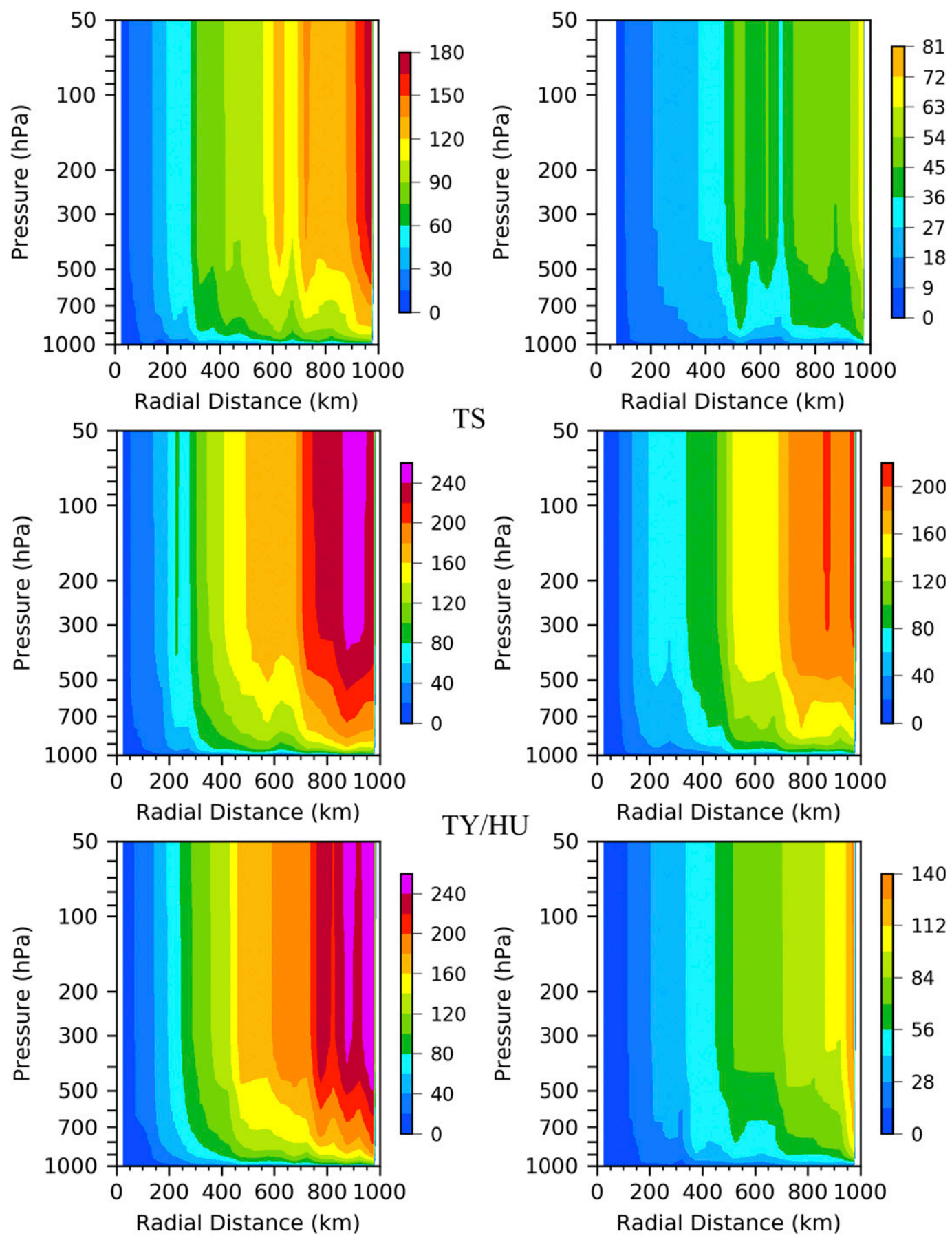

FIG. 7. RO profile counts calculated in each $50-\mathrm{km}$ radial distance and $10-\mathrm{hPa}$ pressure box over the (left) western Pacific and (right) Atlantic Oceans. (top) TD, (middle) TS, and (bottom) TY/HU.

TC-collocated RO temperature profiles, as well as the environmental profiles of temperature and water vapor pressure and its tropopause height that are derived as the average of all $\mathrm{RO}$ profiles with radial distances of $1000-1300 \mathrm{~km}$ near (no more than $1^{\circ}$ away from) the latitude at collocated TC centers. The major warm-core temperature anomaly near the centers of TCs over the western Pacific are located around $250 \mathrm{hPa}$ in the three TD, TS, and TY categories, which are higher than those over the Atlantic Ocean. Over the Atlantic Ocean, the 

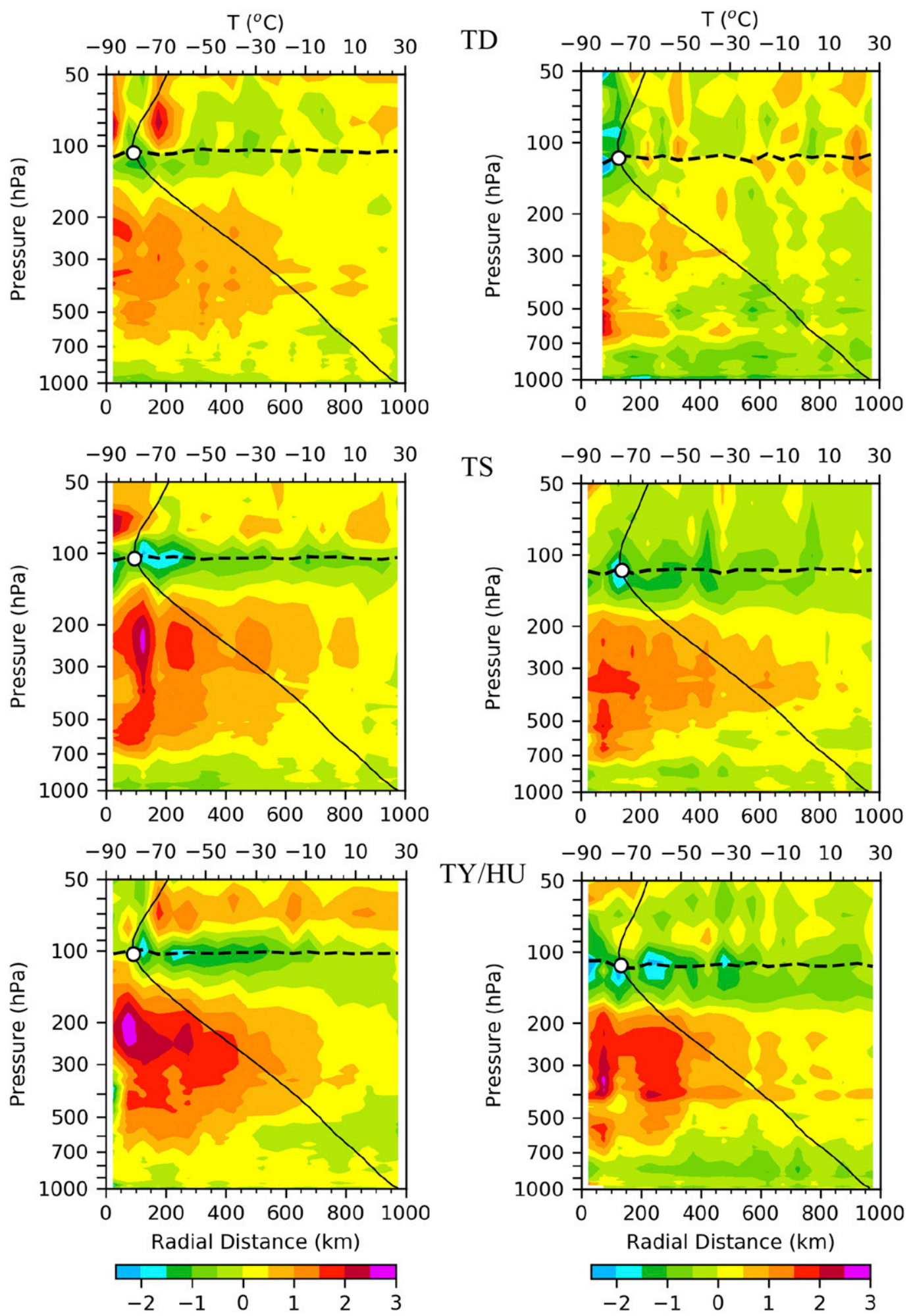

FIG. 8. Composite temperature cross sections (colored shading; ${ }^{\circ} \mathrm{C}$ ) and tropopause height (black dashed lines) for the TD, TS, and TY/HU categories derived from collocated RO data over the (left) western Pacific and (right) Atlantic Oceans. Also shown are mean RO environmental profiles (black solid lines) and the tropopause (white dots) calculated from all collocated ROs with radial distances from 1000 to $1300 \mathrm{~km}$ at the same latitudes as the collocated TC centers. 

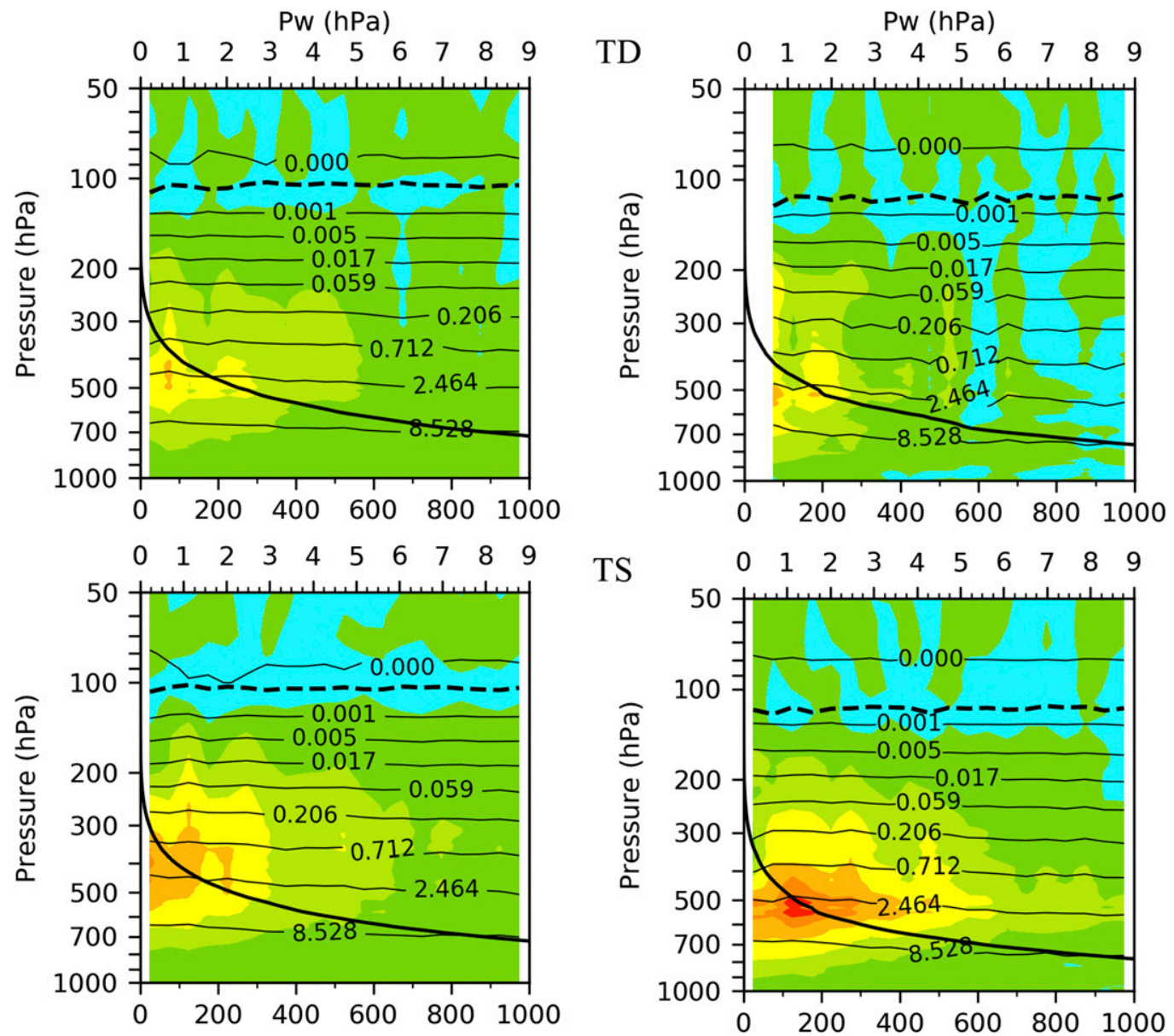

TS
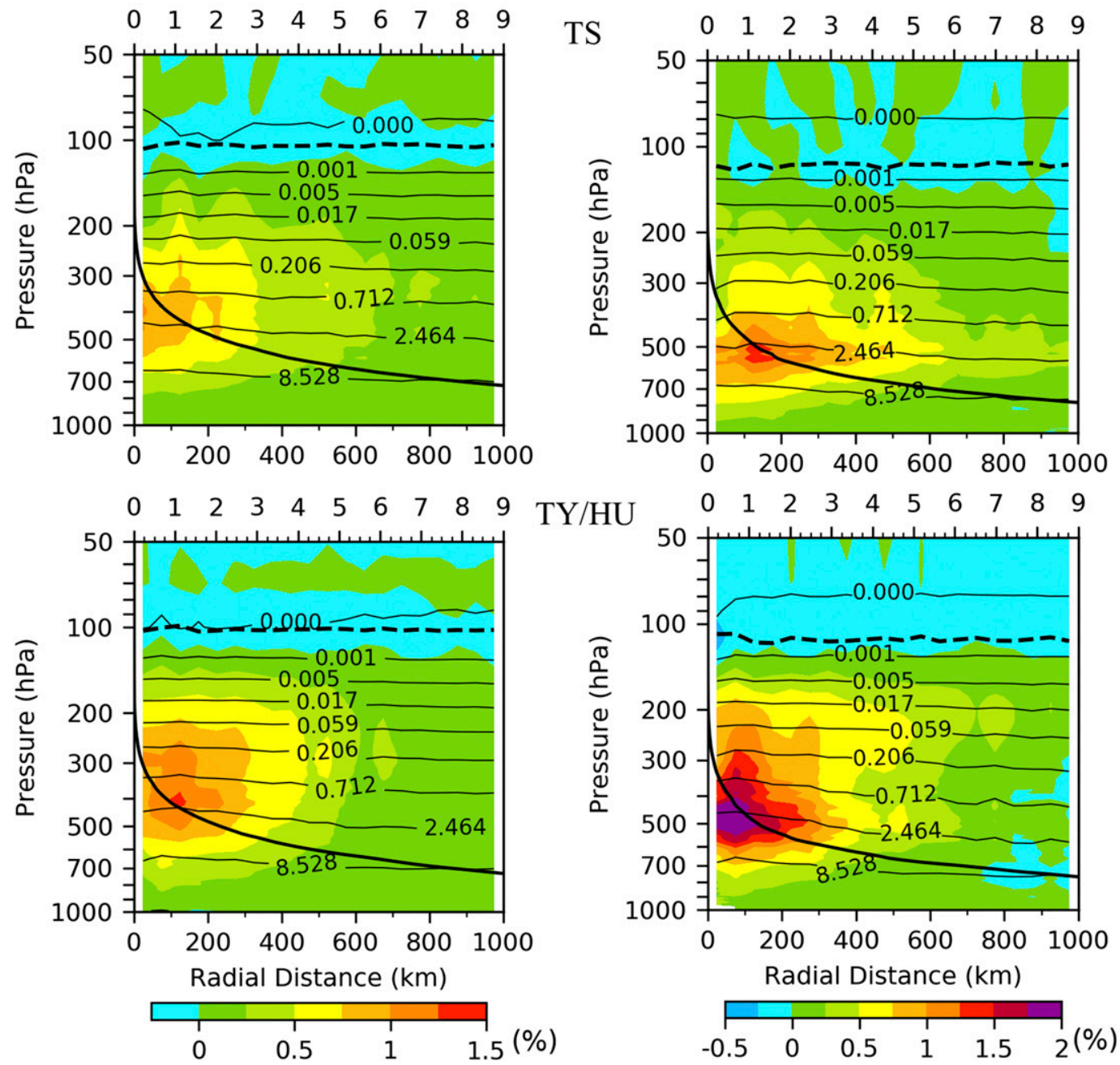

FIG. 9. As in Fig. 8, but for the fractional water vapor pressure anomaly \{calculated as $\left[\left(e-e_{\text {env }}\right) / e_{\text {env }}\right]$; colored shading\}, the water vapor pressure (contour lines; $\mathrm{hPa}$ ), and the vertical profile of the environmental water vapor (Pw; thick black solid lines). The black dashed lines show the tropopause heights. 
TD warm-core temperature anomaly centers are located around $600 \mathrm{hPa}$, and the warm-core centers in the TS and HU categories are located around $350 \mathrm{hPa}$. Of course, the differences in the TC structure between the Atlantic and Pacific Oceans could arise from smaller data counts over the Atlantic than the Pacific Ocean. A secondary maximum warm-core temperature anomaly is found at $\sim 350$ and $600 \mathrm{hPa}$ for TCs in the TD and TS categories over the western Pacific Ocean, respectively, and at $\sim 250,550$, and $600 \mathrm{hPa}$ for TCs in the TD, TS, and HU categories over the Atlantic Ocean, respectively. In the radial direction, there are also secondary warm-core maxima $\sim 200-300 \mathrm{~km}$ that are located at similar altitudes as the warm cores near the center but extend to lower altitudes, except for TDs over the Atlantic Ocean. These secondary warm-core maxima for TDs around $\sim 200-300 \mathrm{~km}$ are found at slightly lower altitudes than their secondary maximum TC warm temperature anomalies. Radial variations in the RO-derived warm-core temperature anomaly generate TC spiral rainband features. As the radial distance increases, there appear third and fourth warm-anomaly bands with weaker and weaker intensities. Another feature worth noting is the band of cold anomalies located near the tropopause, especially for TCs at TS, HU, and TY intensities. This band arises because 1) tropopause altitudes are slightly higher than their environments in the presence of stronger upward motion and convective precipitation within TCs, and 2) the temperature decreases with altitude in the troposphere and increases and/or remains constant with altitude in the stratosphere. The tropopause-level cooling above tropospheric warming was found by Rivoire et al. (2016), who composited the temperature retrievals from COSMIC and the Advanced Microwave Sounding Unit-A (AMSU-A) about the lifetime maximum intensity for worldwide hurricane-strength TCs from 2007 to 2014. The vertically banded tropospheric warmer temperature anomaly in the radial direction corresponds to a series of cold tropopause, cold anomaly maxima.

Figure 9 shows the composite cross sections of the fractional water vapor pressure anomaly \{calculated as $\left.\left[\left(e-e_{\mathrm{env}}\right) / e_{\mathrm{env}}\right]\right\}$, where water vapor pressure $e$ and environmental water vapor pressure $e_{\text {env }}$ are derived from TC-collocated RO observations. TCs within a radial distance of $\sim 600 \mathrm{~km}$ are characterized by wet cores with high water vapor pressure anomalies that are located below the warm cores with high temperature anomalies. The fractional water vapor pressure anomaly increases as the TC intensity increases. The TC wet cores over the western Pacific Ocean are deeper but weaker than those over the Atlantic Ocean. The maximum fractional water vapor pressure anomaly exceeds $1.2 \%$ and $2.0 \%$ for TYs over the western Pacific Ocean and HUs over the Atlantic Ocean, respectively. The lower-altitude contours of the fractional water vapor pressure anomaly are smoother than those of the upper-altitude contours. The fractional water vapor pressure anomalies in the midand upper levels of the troposphere are higher radially where the temperature anomaly is higher at the same radial distances.

The results obtained with GPS RO data for TCs complement those from other data sources, such as dropsonde observations. Dropsonde observations are most populated in the mid- and low troposphere, while GPS RO has more high-quality data in the upper troposphere and higher altitudes. Using a total of 1878 GPS dropsondes, which were deployed by research aircraft in 19 hurricanes and had been postprocessed and quality controlled using the National Center for Atmospheric Research's (NCAR's) Atmospheric Sounding Processing Environment (ASPEN) software (Zhang et al. 2013), Ren (2014) was able to generate a set of composite maps below about $600 \mathrm{hPa}$ from this dataset. Most other dropsonde analyses of hurricanes were typically done for case studies. Halverson et al. (2006) presented a composite structure of the warm anomaly across a vertical slice through Hurricane Erin on 10 September 2001 using dropsondes that were released from heights of $11-12 \mathrm{~km}$ during the Fourth Convection and Moisture Experiment (CAMEX-4) program. The instantaneous warm temperature anomalies spread horizontally with increasing height, with the highest values of more than $9^{\circ} \mathrm{C}$ maintained through a deep layer from 300 down to 750 hPa. Komaromi and Doyle (2017, hereafter KD17) showed an advantage of the dropsondes' sampling capability of the inner-core warm anomaly through the entire depth of TCs. The dropsondes were released by the Global Hawk AV-6 aircraft, which released dropsondes from the lower stratosphere. The composite maps of warm cores in both the binned radius-pressure azimuthal-mean cross sections (Fig. 12 in KD17) and the innermost $0-25-\mathrm{km}$ radial-mean temperature anomaly (Fig. 14 in KD17) showed a distinct double-warm-core structure, with the largest maximum around $200 \mathrm{hPa}$ and a second smaller maximum around $800 \mathrm{hPa}$. They argued that the upper-level warm core is actually a stratospheric intrusion, and the actual upper-level vortex was associated with the observed cold core between the two warm cores.

The TC warm and wet cores obtained from GPS RO observations in Figs. 8 and 9 suggest size differences between western Pacific Ocean and Atlantic Ocean TCs. To confirm this, Fig. 10 shows the means and standard deviations of $34-, 50-$, and $64-\mathrm{kt}\left(1 \mathrm{kt} \approx 0.51 \mathrm{~m} \mathrm{~s}^{-1}\right)$ wind radii for all TCs over the western Pacific and Atlantic 


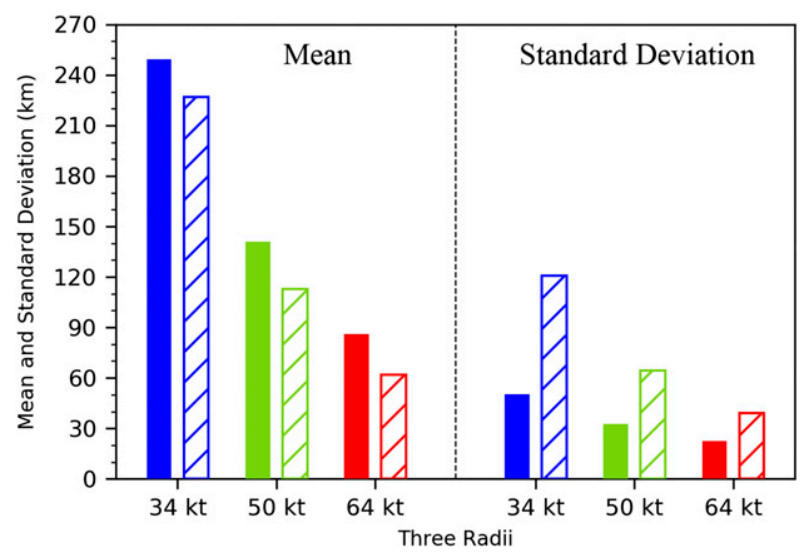

FIG. 10. (left) Mean and (right) standard deviation of 34-, 50-, and 64-kt wind radii for all TCs collocated with RO data over the western Pacific (solid bars) and Atlantic (dashed bars) Oceans.

Oceans collocated with the RO profiles shown in Figs. 49. On average, the 34-, 50-, and 64-kt wind radii for TCs over the western Pacific Ocean are $\sim 250,140$, and $85 \mathrm{~km}$, respectively, and those for TCs over the Atlantic Ocean are $\sim 228,114$, and $64 \mathrm{~km}$, respectively. The wind radii of TCs over the Atlantic Ocean are about $20 \mathrm{~km}$ smaller than those over the western Pacific Ocean. The standard deviations of the 34-, 50-, and 64-kt wind radii for TCs over the western Pacific Ocean are $~ 50,30$, and $20 \mathrm{~km}$, respectively, which are more than half those of TCs over the Atlantic Ocean. In other words, the TC size variability is much larger over the Atlantic Ocean than over the western Pacific Ocean. While the composite analysis of TCs presented in this study provides a general characterization of the TC structure, a drawback is that compositing could possibly smooth important structural details among a large number of TCs of different sizes.

There are different definitions of the TC size. Knaff et al. (2014) developed an objective method based on satellite infrared imager observations and global NWP analyses and examined the TC size climatology for 1995-2011. They defined the TC size as the radius of 5-kt winds. They found that the TC size climatology is basin specific, with the largest TC size distribution over the western North Pacific Ocean (Knaff et al. 2014). Using the high resolution and high precision of QuikSCAT data for the years 1999-2008, Chavas and Emanuel (2010) derived the TC size as the radius of vanishing winds calculated using an outer wind structure model that assumes vanishing deep convection beyond the azimuthally averaged radius of $12 \mathrm{~m} \mathrm{~s}^{-1}$ winds. They concluded that the global distribution of TC size is approximately lognormal. The QuikSCAT-derived TC sizes over 2000-09 matched the outer TC size in four atmospheric reanalysis datasets more closely for smaller TC sizes in both basins and TCs in the lower latitudes in western North Pacific basin (Schenkel et al. 2017). When more GPS RO data become available in the future, we plan to group these data collocated with TCs according to the TC size.

\section{Importance of quality control}

A lesson learned for constructing TC temperature and water vapor climatologies over the Atlantic and Pacific Oceans from GPS RO observations is the extreme importance of QC. Figure 11 shows what would have been obtained by simply removing only those data flagged as "bad" without taking the additional QC steps previously described. The composite temperature cross sections for TSs that would have been derived from TS-collocated RO data over the western Pacific Ocean without any additional QC and after doing the range check QC step are shown in the top and bottom panels, respectively, of Fig. 11. Unrealistically large temperature anomalies $(>23 \mathrm{~K})$ appear in several places. Results in Fig. 11 can be compared with the middle panels in Fig. 8. The TS temperature climatology over the western Pacific Ocean, without excluding outliers, not only makes these figures messy, but also greatly distorts the warm-core structures. Both the intensity and size of the TS warm cores are changed over both the Pacific and Atlantic Oceans. Differences between Figs. 11 and 8 near and above the tropopause altitude are also quite large.

Similar results are obtained for all other composite cross-sections of temperatures and water vapor pressures shown in Figs. 8 and 9 (figures omitted).

\section{Summary and conclusions}

The purpose of this paper is to construct separate sets of TC temperature and water vapor climatologies over the Atlantic and western Pacific Oceans using multiple years of GPS RO observations. We demonstrated that an effective quality control procedure is important for generating meaningful results when dealing with a large set of RO data. Differences in the intensities and structures of TCs, TSs, and TYs/HUs over the two oceanic regions are shown. It was found that the warmcore temperature anomalies of TCs over the western Pacific are stronger, deeper, and located in higher altitudes than those over the Atlantic Ocean. The water vapor anomalies within TCs over the Atlantic Ocean are larger than those over the western Pacific, due probably to lower altitudes of the warm-core temperature anomalies of TCs over the Atlantic Ocean. The proposed generation of TC structure requirements is purely 

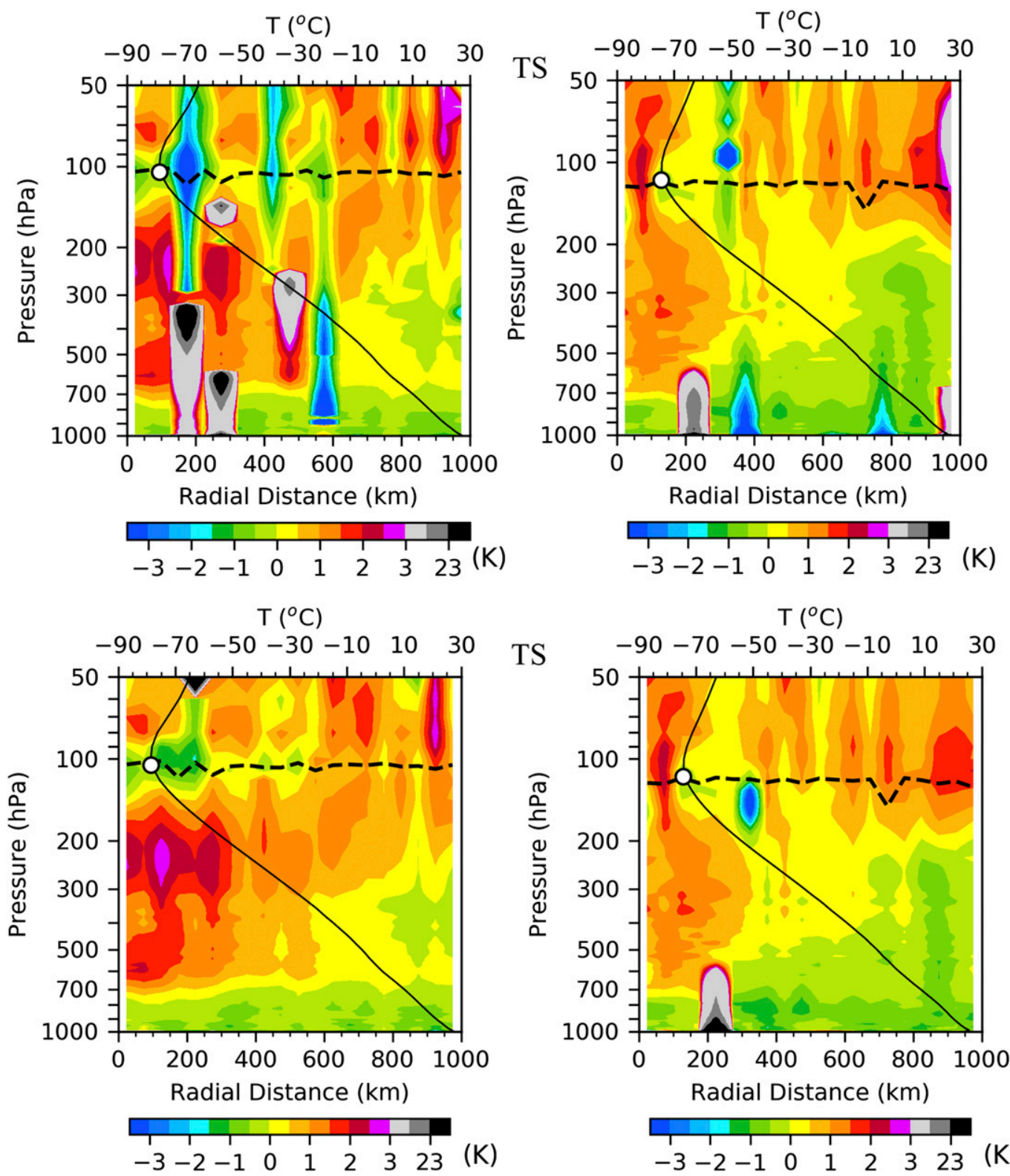

FIG. 11. As in the middle panels of Fig. 8, but for results (top) without QC and (bottom) after the first step of QC. The color bar has been expanded to include additional temperature ranges: 3-13 (light gray), 13-23 (dark gray), and 23-63 K (black).

observation based with no model input. Results are appropriate for incorporation into data assimilation systems not only for numerical weather prediction, but also for global reanalysis for climate purposes. The temperature and water vapor structures generated for TCs over both oceans can serve as a background weak constraint to spin up vertical wind fields not readily observed.

Because of a lack of sufficient observations within the TC inner core-commonly referred to as the strongest part of the TC circulation, including the eye, eyewall, and its immediate vicinity and usually spanning the radius range of around $100-200 \mathrm{~km}$ - the results in this study cannot be used as a solid climatology of TC innercore structures. The future six-satellite constellation COSMIC-2, which is scheduled to be launched in fall 2018 , has an inclination that is 3 times smaller $\left(24^{\circ}\right)$ than that of COSMIC $\left(72^{\circ}\right)$ to allow many more GPS RO data to be made available in the tropics where TCs are populated. The more powerful antennae, a sampling rate 2 times higher than that of COSMIC, and more advanced retrieval techniques would provide highquality GPS RO data as well. Applications of GPS RO 
data for understanding and modeling TC inner cores will be further explored and compared with those from dropsondes in the future studies. A possibility is to select only those RO data whose ray paths are nearly perpendicular to the eyewall of TCs, given the consideration that the across-track resolution of GPS RO data is very high $(\sim 1.4 \mathrm{~km})$.

The results obtained in this study using COSMIC and MetOp-A/MetOp-B GPS RO-retrieved temperature and moisture to construct a climatology of the TC structures are complementary to those results obtained from other types of observations, such as polar-orbiting satellite microwave, geostationary satellite infrared, airborne radar, and aircraft dropsonde data. The TC warm-core temperature retrievals from satellite microwave temperature sounding observations are accurate in the upper troposphere but not good in the low and midtroposphere due to rain contamination in regions of heavy precipitation in TCs (Kidder et al. 2000; Tian and Zou 2018).

Satellite data assimilation with the vortex background fields proposed in this study will be tested to see whether they increase the TC analysis accuracy and reduce TC forecast errors. The performance of the proposed vortex scheme on weak and strong vortices needs to be assessed separately, which we plan to do in future work. Given the current advances in the resolutions and physical parameterizations of numerical forecast models and in data assimilation methodologies, as well as the abundance of satellite observations, it may be possible to predict the track, intensity, and inner-core structures of HUs and TYs reasonably well using RO-derived TC inner-core temperature and water vapor climatologies over both the Atlantic and Pacific Oceans.

Acknowledgments. The authors thank the NCAR scientists in the COSMIC team for providing all RO data used in this study. This research was supported by the National Natural Science Foundation of China Grants 91337218 and 41875032, by the National Oceanic and Atmospheric Administration (NOAA) Grant NA14NES4320003, and by Jiangsu Qinglan Project.

\section{REFERENCES}

Anthes, R. A., and Coauthors, 2008: The COSMIC/FORMOSAT3 mission: Early results. Bull. Amer. Meteor. Soc., 89, 313-334, https://doi.org/10.1175/BAMS-89-3-313.

Cangialosi, J., and J. Franklin, 2011: 2010 National Hurricane Center verification report. NOAA/National Hurricane Center Rep., 77 pp., http://origin.www.nhc.noaa.gov/verification/pdfs/ Verification_2010.pdf.

Chavas, D. R., and K. A. Emanuel, 2010: A QuikSCAT climatology of tropical cyclone size. Geophys. Res. Lett., 37, L18816, https://doi.org/10.1029/2010GL044558.
Elsberry, R., 1995: Recent advancements in dynamical tropical cyclone track predictions. Meteor. Atmos. Phys., 56, 81-99, https://doi.org/10.1007/BF01022522.

Fujita, T., 1952: Pressure distribution within a typhoon. Geophys. Mag., 23, 437-451.

Gall, R., J. Franklin, F. Marks, E. N. Rappaport, and F. Toepfer, 2013: The Hurricane Forecast Improvement Project. Bull. Amer. Meteor. Soc., 94, 329-343, https://doi.org/10.1175/ BAMS-D-12-00071.1.

Halverson, J. B., J. Simpson, G. Heymsfield, H. Pierce, T. Hock, and L. Ritchie, 2006: Warm core structure of Hurricane Erin diagnosed from high altitude dropsondes during CAMEX-4. J. Atmos. Sci., 63, 309-324, https://doi.org/10.1175/ JAS3596.1.

Honda, T., and Coauthors, 2018: Assimilating all-sky Himawari-8 satellite infrared radiances: A case of Typhoon Soudelor (2015). Mon. Wea. Rev., 146, 213-229, https://doi.org/10.1175/ MWR-D-16-0357.1.

Janjic, Z. I., 2003: A nonhydrostatic model based on a new approach. Meteor. Atmos. Phys., 82, 271-285, https://doi.org/ 10.1007/s00703-001-0587-6.

— J. J. P. Gerrity Jr., and S. Nickovic, 2001: An alternative approach to nonhydrostatic modeling. Mon. Wea. Rev., 129, 1164-1178, https://doi.org/10.1175/1520-0493(2001)129<1164: AAATNM $>2.0 . C O ; 2$.

Kidder, S. Q., M. D. Goldberg, R. M. Zehr, M. DeMaria, J. F. W. Purdom, C. S. Velden, N. C. Grody, and S. J. Kusselson, 2000: Satellite analysis of tropical cyclones using the Advanced Microwave Sounding Unit (AMSU). Bull. Amer. Meteor. Soc., 81, 1241-1260, https://doi.org/10.1175/1520-0477(2000)081<1241: SAOTCU $>2.3 . \mathrm{CO} ; 2$.

Knaff, J. A., S. P. Longmore, and D. A. Molenar, 2014: An objective satellite-based tropical cyclone size climatology. J. Climate, 27, 455-476, https://doi.org/10.1175/JCLI-D-13-00096.1.

Knutson, T. R., and Coauthors, 2010: Tropical cyclones and climate change. Nat. Geosci., 3, 157-163, https://doi.org/10.1038/ ngeo779.

Komaromi, W. A., and J. D. Doyle, 2017: Tropical cyclone outflow and warm core structure as revealed by HS3 dropsonde data. Mon. Wea. Rev., 145, 1339-1359, https://doi.org/10.1175/ MWR-D-16-0172.1.

Kuo, Y.-H., T.-K. Wee, S. Sokolovskiy, C. Rocken, W. Schreiner, D. Hunt, and R. Anthes, 2004: Inversion and error estimation of GPS radio occultation data. J. Meteor. Soc. Japan, 82, 507531, https://doi.org/10.2151/jmsj.2004.507.

Kurihara, Y., M. A. Bender, R. E. Tuleya, and R. J. Ross, 1990: Prediction experiments of Hurricane Gloria (1985) using a multiply nested movable mesh model. Mon. Wea. Rev., 118, 2185-2198, https://doi.org/10.1175/1520-0493(1990)118<2185: PEOHGU $>2.0 . \mathrm{CO} ; 2$.

,$- \ldots$, and R. J. Ross, 1993: An initialization scheme of hurricane models by vortex specification. Mon. Wea. Rev., 121, 2030-2045, https://doi.org/10.1175/1520-0493(1993)121<2030: AISOHM $>2.0 . \mathrm{CO} ; 2$.

Kursinski, E., and Coauthors, 1996: Initial results of radio occultation observations of Earth's atmosphere using the global positioning system. Science, 271, 1107-1110, https://doi.org/ 10.1126/science.271.5252.1107.

Lanzante, J. R., 1996: Resistant, robust and non-parametric techniques for the analysis of climate data: Theory and examples, including applications to historical radiosonde station data. Int. J. Climatol., 16, 1197-1226, https://doi.org/10.1002/ (SICI)1097-0088(199611)16:11<1197::AID-JOC89>3.0.CO;2-L. 
Liu, Y., D.-L. Zhang, and M. Yau, 1997: A multiscale numerical study of Hurricane Andrew (1992). Part I: Explicit simulation and verification. Mon. Wea. Rev., 125, 3073-3093, https://doi.org/ 10.1175/1520-0493(1997)125<3073:AMNSOH>2.0.CO;2.

Lord, S. J., 1991: A bogusing system for vortex circulations in the National Meteorological Center global forecast model. Preprints, 19th Conf. on Hurricanes and Tropical Meteorology, Miami, FL, Amer. Meteor. Soc., 328-330.

Marks, F. D., Jr., and R. A. Houze Jr., 1987: Inner core structure of Hurricane Alicia from airborne Doppler radar observations. J. Atmos. Sci., 44, 1296-1317, https://doi.org/10.1175/ 1520-0469(1987)044<1296:ICSOHA > 2.0.CO;2.

Park, K., and X. Zou, 2004: Toward developing an objective 4DVAR BDA scheme for hurricane initialization based on TPC observed parameters. Mon. Wea. Rev., 132, 2054-2069, https://doi.org/10.1175/1520-0493(2004)132<2054: TDAODB $>2.0 . \mathrm{CO} ; 2$

Ren, W., 2014: Radial-vertical profiles of tropical cyclone derived from dropsondes. M.S. thesis, Dept. of Earth, Ocean, and Atmospheric Science, Florida State University, $77 \mathrm{pp}$.

Rivoire, L., T. Birner, and J. A. Knaff, 2016: Evolution of the upper-level thermal structure in tropical cyclones. Geophys. Res. Lett., 43, 10 530-10 537, https://doi.org/10.1002/ 2016GL070622.

Schenkel, B. A., N. Lin, D. Chavas, M. Oppenheimer, and A. Brammer, 2017: Evaluating outer tropical cyclone size in reanalysis datasets using QuikSCAT data. J. Climate, 30, 8745-8762, https://doi.org/10.1175/JCLI-D-17-0122.1.

Tian, X., and X. Zou, 2018: Capturing size and intensity changes of Hurricanes Irma and Maria (2017) from polar-orbiting satellite microwave radiometers. J. Atmos. Sci., 75, 2509-2522, https://doi.org/10.1175/JAS-D-17-0315.1.

Trinh, V. T., and T. N. Krishnamurti, 1992: Vortex initialization for typhoon track prediction. Meteor. Atmos. Phys., 47, 117-126, https://doi.org/10.1007/BF01025612.
Xiao, Q., X. Zou, and B. Wang, 2000: Initialization and simulation of a landfalling hurricane using a variational bogus data assimilation scheme. Mon. Wea. Rev., 128, 2252-2269, https:// doi.org/10.1175/1520-0493(2000)128<2252:IASOAL >2.0.CO;2.

Zhang, F., Y. Weng, J. A. Sippel, Z. Meng, and C. H. Bishop, 2009: Cloud-resolving hurricane initialization and prediction through assimilation of Doppler radar observations with an ensemble Kalman filter. Mon. Wea. Rev., 137, 2105-2125, https://doi.org/ 10.1175/2009MWR2645.1.

- M. Minamide, and E. E. Clothiaux, 2016: Potential impacts of assimilating all-sky infrared satellite radiances from GOES-R on convection-permitting analysis and prediction of tropical cyclones. Geophys. Res. Lett., 43, 2954-2963, https:/doi.org/ 10.1002/2016GL068468.

Zhang, J. A., R. F. Rogers, P. Reasor, E. Uhlhorn, and F. D. Marks Jr., 2013: Asymmetric hurricane boundary layer structure from dropsonde composites in relation to the environmental vertical wind shear. Mon. Wea. Rev., 141, 3968-3984, https:// doi.org/10.1175/MWR-D-12-00335.1.

Zou, X., and Q. Xiao, 2000: Studies on the initialization and simulation of a mature hurricane using a variational bogus data assimilation scheme. J. Atmos. Sci., 57, 836-860, https:// doi.org/10.1175/1520-0469(2000)057<0836:SOTIAS > 2.0.CO;2.

, and Z. Zeng, 2006: A quality control procedure for GPS radio occultation data. J. Geophys. Res., 111, D02112, https:// doi.org/10.1029/2005JD005846.

, F. Weng, B. Zhang, L. Lin, Z. Qin, and V. Tallapragada, 2013: Impacts of assimilation of ATMS data in HWRF on track and intensity forecasts of 2012 four landfall hurricanes. J. Geophys. Res. Atmos., 118, 11 558-11 576, https://doi.org/ 10.1002/2013JD020405.

, Z. Qin, and Y. Zheng, 2015: Improved tropical storm forecasts with GOES-13/15 imager radiance assimilation and asymmetric vortex initialization in HWRF. Mon. Wea. Rev., 143, 2485-2505, https://doi.org/10.1175/MWR-D-14-00223.1. 